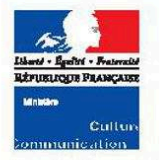

Secrétariat général

Délégation

au développement

et aux affaires

internationales

Département
des études,

de la prospective
et des statistiques
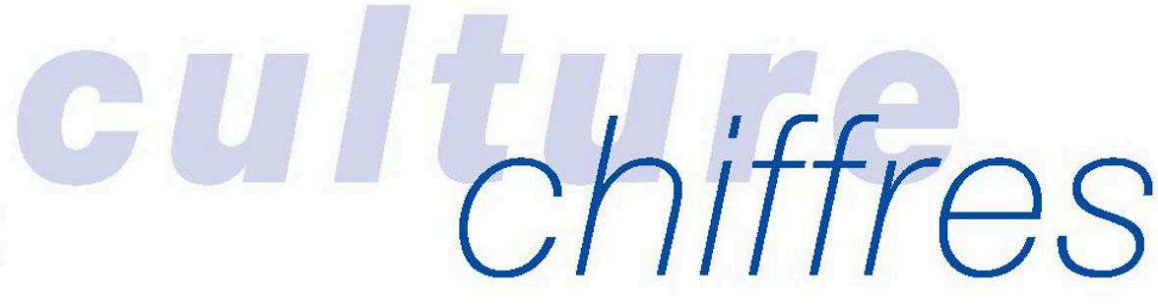

182, rue Saint-Honoré, 75033 Paris cedex 01

풍 0140157913 - 国 0140157999

\title{
Les établissements d'enseignement supérieur artistique et culturel
}

\section{Effectifs et diplômes. Année scolaire 2006-2007}

\author{
Edwige Zadora**
}

L'enseignement supérieur artistique et culturel dépendant du ministère de la Culture et de la Communication se caractérise par une grande diversité institutionnelle. Il relève d'établissements d'enseignement spécialisé publics et privés de taille et de statut très variés. Certains d'entre eux sont des établissements publics sous tutelle du ministère de la Culture et de la Communication, d'autres sont des établissements gérés par des collectivités locales, d'autres enfin des structures privées qui bénéficient parfois de subventions publiques.

Il repose également sur des formations universitaires ou d'autres formations relevant du ministère de l'Éducation nationale, celles par exemple qui conduisent au brevet de technicien supérieur (BTS) ou au diplôme des métiers d'art (DMA).

Les données présentées ici concernent les formations aux métiers artistiques dans les domaines du spectacle, des arts plastiques, de l'architecture, du patrimoine, du cinéma et de l'audiovisuel pour l'année scolaire 2006-2007 ${ }^{1}$ dans les établissements d'enseignement supérieur artistique et culturel dépendant du ministère de la Culture et de la Communication - établissements sous tutelle ou contrôle pédagogique du ministère ou subventionné par lui ${ }^{2}$.

\section{LES ÉLÈVES}

L'enseignement supérieur artistique et culturel dépendant du ministère de la Culture et de la Communication est dispensé dans $118^{3}$ établissements. Pour l'année scolaire 2006-2007, ces établissements ont accueilli plus de 35000 élèves, dont près de 10500 sont inscrits dans les écoles d'arts plastiques et plus de 19000 dans les écoles d'architecture. Les écoles qui forment aux métiers du spectacle vivant et de l'audiovisuel et celles qui forment aux métiers du patrimoine ont accueilli respectivement 3800 et 1800 élèves.

Si les enseignements artistiques et culturels sont suivis en majorité par des femmes - elles représentent $56 \%$ de l'effectif total des étudiants -, on note des différences significatives suivant les domaines artistiques. Elles prédominent dans les formations patrimoniales $(80 \%)$, en arts plastiques $(63 \%)$ et dans les formations musicales et chorégraphiques $(55 \%)$, alors que les hommes sont plus nombreux dans les écoles de cinéma et audiovisuel ( $57 \%$ ). Dans les formations aux métiers du théâtre et des spectacles et dans les écoles d'architecture, les pro-

* Les tableaux statistiques détaillés par domaine et par école sont consultables en ligne http://www.culture.gouv.fr/deps ** Chargée d'études au sein de l'Equipe statistique du Deps.

1. Pour l'année scolaire 2005-2006, voir Note statistique du Deps 24, janvier 2007, téléchargeable sur http://www.

2. Liste des etablissements fournie par le Département de l'éducation, des formations, des enseignements et des métiers du ministère de la Culture et de la Communication.

3. Implantée sur deux sites, Angoulême et Poitiers, l'École superieure de l'image est comptée ici comme une seule école 


\section{Les établissements d'enseignement supérieur artistique et culturel}

Effectifs et diplômes_Année scolaire 2006-2007

\section{Edwige Zadora}

Éditeur : Département des études, de la prospective et des statistiques

Lieu d'édition : Paris

Année d'édition : 2008

Date de mise en ligne : 21 septembre 2015

Collection : Culture chiffres

ISBN électronique : 9782111398368

\section{Oonentition \\ Qbooks}

http://books.openedition.org

\section{Édition imprimée}

Date de publication : 1 janvier 2008

Nombre de pages : 4

\section{Référence électronique}

ZADORA, Edwige. Les établissements d'enseignement supérieur artistique et culturel : Effectifs et diplômes _ Année scolaire 2006-2007. Nouvelle édition [en ligne]. Paris : Département des études, de la prospective et des statistiques, 2008 (généré le 25 avril 2021). Disponible sur Internet : <http:// books.openedition.org/deps/793>. ISBN : 9782111398368.

(C) Département des études, de la prospective et des statistiques, 2008

Creative Commons - Attribution - Pas d'Utilisation Commerciale 3.0 non transposé - CC BY-NC 3.0 

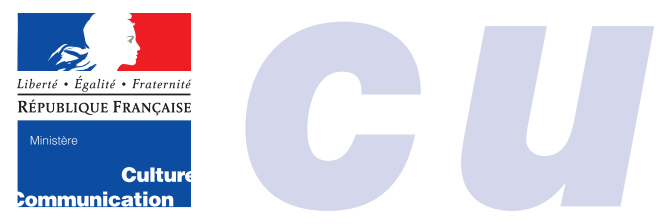

Secrétariat général

Délégation

au développement

et aux affaires

internationales

Département

des études,

de la prospective

et des statistiques

\title{
Les établissements d'enseignement supérieur artistique et culturel
}

\section{Effectifs et diplômes. Année scolaire 2006-2007*}

\author{
Edwige Zadora**
}

L'enseignement supérieur artistique et culturel dépendant du ministère de la Culture et de la Communication se caractérise par une grande diversité institutionnelle. Il relève d'établissements d'enseignement spécialisé publics et privés de taille et de statut très variés. Certains d'entre eux sont des établissements publics sous tutelle du ministère de la Culture et de la Communication, d'autres sont des établissements gérés par des collectivités locales, d'autres enfin des structures privées qui bénéficient parfois de subventions publiques.

Il repose également sur des formations universitaires ou d'autres formations relevant du ministère de l'Éducation nationale, celles par exemple qui conduisent au brevet de technicien supérieur (BTS) ou au diplôme des métiers d'art (DMA).

Les données présentées ici concernent les formations aux métiers artistiques dans les domaines du spectacle, des arts plastiques, de l'architecture, du patrimoine, du cinéma et de l'audiovisuel pour l'année scolaire 2006-2007 dans les établissements d'enseignement supérieur artistique et culturel dépendant du ministère de la Culture et de la Communication - établissements sous tutelle ou contrôle pédagogique du ministère ou subventionné par lui ${ }^{2}$.

\section{LES ÉLÈVES}

L'enseignement supérieur artistique et culturel dépendant du ministère de la Culture et de la Communication est dispensé dans $118^{3}$ établissements. Pour l'année scolaire 2006-2007, ces établissements ont accueilli plus de 35000 élèves, dont près de 10500 sont inscrits dans les écoles d'arts plastiques et plus de 19000 dans les écoles d'architecture. Les écoles qui forment aux métiers du spectacle vivant et de l'audiovisuel et celles qui forment aux métiers du patrimoine ont accueilli respectivement 3800 et 1800 élèves.

Si les enseignements artistiques et culturels sont suivis en majorité par des femmes - elles représentent $56 \%$ de l'effectif total des étudiants -, on note des différences significatives suivant les domaines artistiques. Elles prédominent dans les formations patrimoniales $(80 \%)$, en arts plastiques $(63 \%)$ et dans les formations musicales et chorégraphiques (55\%), alors que les hommes sont plus nombreux dans les écoles de cinéma et audiovisuel (57\%). Dans les formations aux métiers du théâtre et des spectacles et dans les écoles d'architecture, les pro-

\footnotetext{
* Les tableaux statistiques détaillés par domaine et par école sont consultables en ligne http://www.culture.gouv.fr/deps

** Chargée d'études au sein de l'équipe statistique du DEPS.

1. Pour l'année scolaire 2005-2006, voir Note statistique du Deps 24, janvier 2007, téléchargeable sur http://www.

2. Liste des établissements fournie par le Département de l'éducation, des formations, des enseignements et des métiers du ministère de la

Culture et de la Communication.

3. Implantée sur deux sites, Angoulême et Poitiers, l'École supérieure de l'image est comptée ici comme une seule école.
} 
portions sont sensiblement les mêmes (respectivement $51 \%$ et $49 \%$ ).

Sur l'ensemble des formations, les étudiants étrangers représentent $14 \%$. On les trouve essentiellement dans la filière architecture $(16 \%)$.

Les établissements d'enseignement artistique et culturel dépendant du ministère de la Culture et de la Communication couvrent l'ensemble du territoire national, à l'exception de la Corse qui ne dispose d'aucune école.

Dans le domaine des arts plastiques et arts appliqués, chaque région dispose d'au moins une école alors que les formations aux métiers du patrimoine et celles du cinéma et de l'audiovisuel ne sont proposées qu'en Île-de-France.

Trois régions - Île-de-France, Provence-AlpesCôte d'Azur et Rhône-Alpes - concentrent 58 \% d'élèves préparant une formation artistique dans
Graphique 1 - Répartition des élèves par domaine (année scolaire 2006-2007)

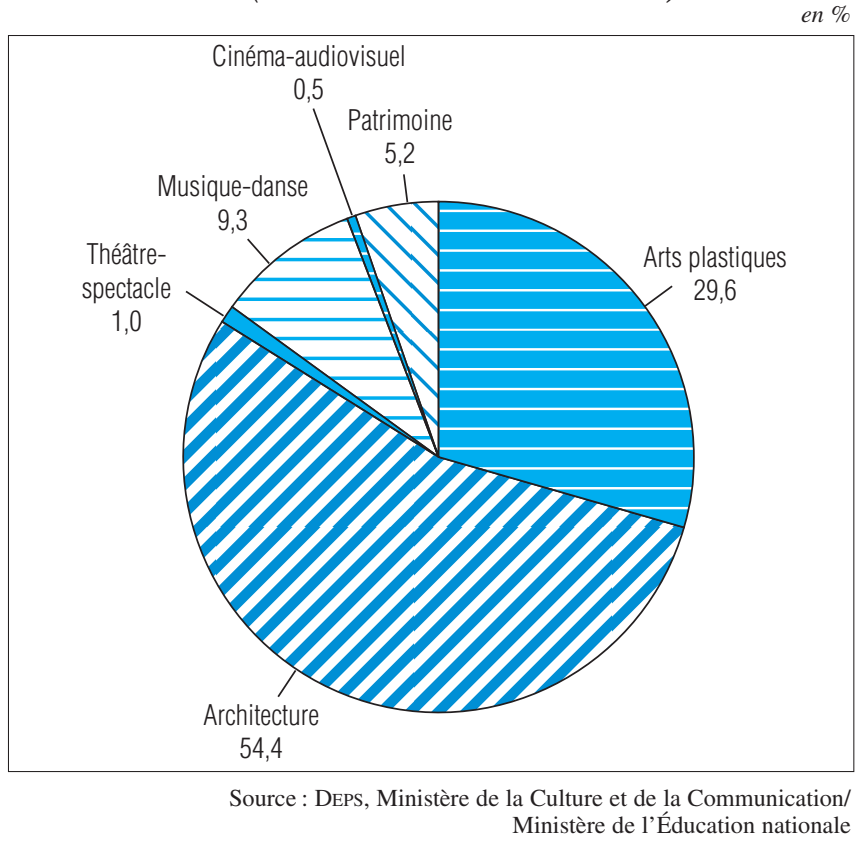

Tableau 1 - Répartition des élèves par domaine et par sexe (année scolaire 2006-2007)

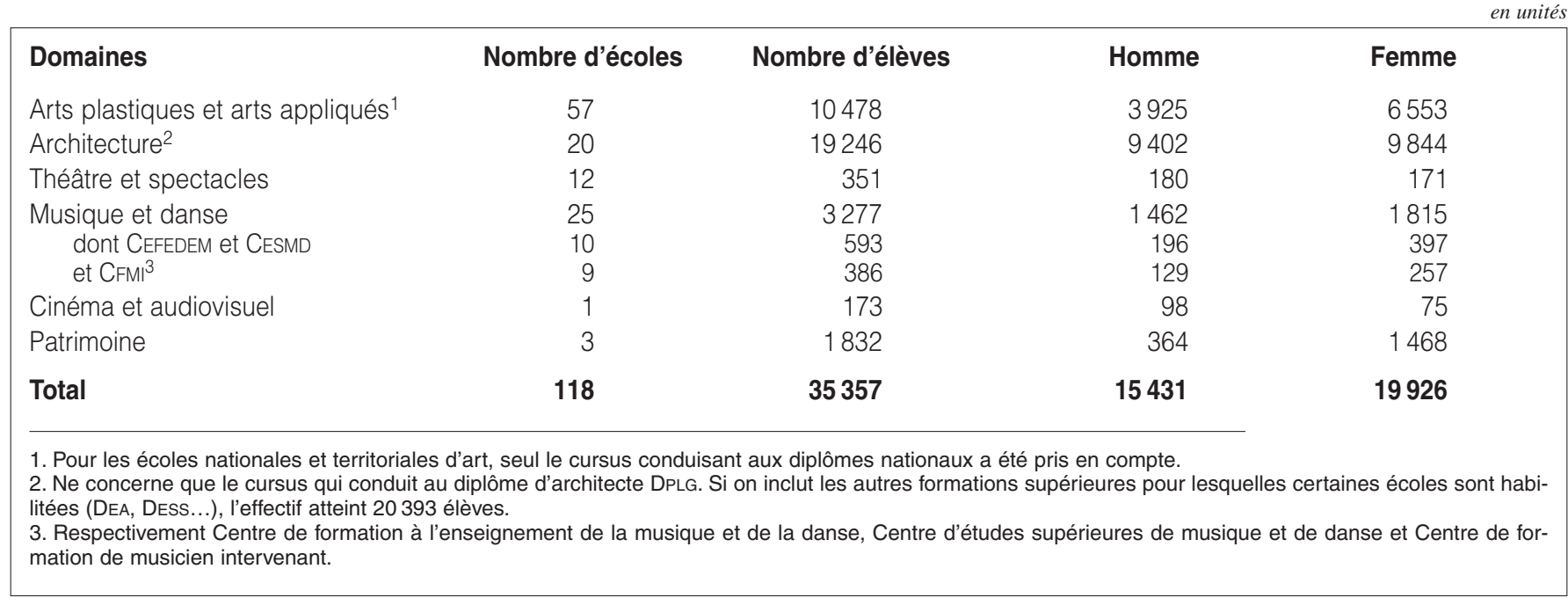

Graphique 2 - Répartition des élèves par domaine et par sexe (année scolaire 2006-2007)

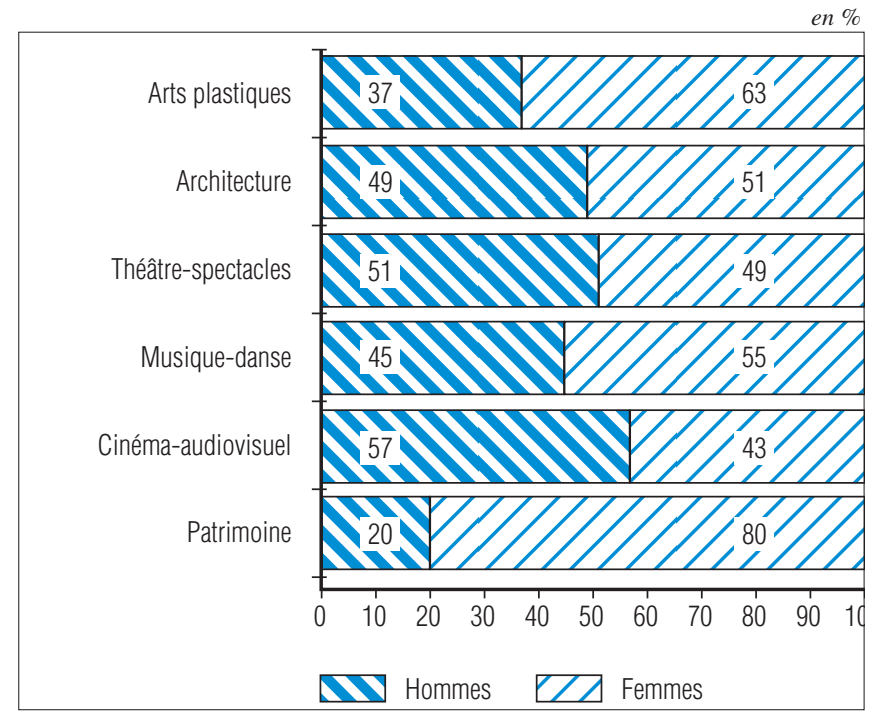

Source : DEPS, Ministère de la Culture et de la Communication/ Ministère de l'Éducation nationale
Tableau 2 - Répartition des élèves par domaine et par origine (année scolaire 2006-2007)

\begin{tabular}{|lrcc|}
\hline Domaines & Total & Français & Étran unités et en \% \\
Arts plastiques & & & \\
$\quad$ et arts appliqués & 10478 & 88 & 12 \\
Architecture & 19246 & 84 & 16 \\
Théâtre et spectacles & 351 & 88 & 12 \\
Musique et danse & 3277 & 88 & 12 \\
$\quad$ dont CEFEDEM et CESMD & 593 & 97 & 3 \\
$\quad$ et CFMl & 386 & 97 & 3 \\
Cinéma et audiovisuel & 173 & 92 & 8 \\
Patrimoine & 1832 & 93 & 7 \\
Total & $\mathbf{3 5 3 5 7}$ & $\mathbf{8 6}$ & $\mathbf{1 4}$ \\
\hline
\end{tabular}


une des écoles dépendant du ministère de la Culture et de la Communication. La concentration des effectifs en Île-de-France (41\%) est principalement due aux écoles d'architecture qui, avec six écoles, regroupent $46 \%$ des étudiants en cette matière.

\section{LES DIPLÔMES}

Les formations supérieures artistiques et culturelles aboutissent à trois types de diplômes :

- des diplômes nationaux de l'enseignement supérieur, au sens du décret du 27 novembre 1997, qui concernent les $1^{\mathrm{er}}$ et $2^{\mathrm{e}}$ cycles des écoles d'architecture ;

- des diplômes nationaux créés par décrets et délivrés au nom de l'État par le ministère de la Culture et de la Communication ou par le ministère de l'Éducation nationale. Dans le premier cas il s'agit des diplômes des écoles d'art (diplôme national d'arts plastiques [DNAP], diplôme natio- nal d'arts et techniques [DNAT], diplôme national supérieur d'expression plastique [DNSEP]) et de ceux des écoles d'architecture (diplômé par le gouvernement [DPLG] et habilitation à l'exercice de la maîtrise d'œuvre en son nom propre [HMONP]). Il s'agit également des diplômes d'enseignement (diplôme d'État ${ }^{4}$ [DE] et certificat d'aptitude [CA] aux fonctions de professeur de musique et de danse) ainsi que du diplôme de restaurateur du patrimoine préparé à l'Institut national du patrimoine et reconnu, depuis 2005, au grade de master. Les diplômes des métiers d'art (DMA), des écoles de cirque ou de l'école de la marionnette et le brevet artistique des techniques du cirque (BATC) sont délivrés par le ministère de l'Éducation nationale ;

- des diplômes d'établissement comme ceux délivrés par les écoles nationales supérieures d'art parisiennes et des diplômes d'université comme les diplômes universitaires de musicien intervenant (DUMI).

Tableau 3 - Répartition des élèves par région et par domaine (année scolaire 2006-2007)

\begin{tabular}{|c|c|c|c|c|c|c|c|c|}
\hline Région & $\begin{array}{l}\text { Nombre } \\
\text { d'écoles }\end{array}$ & $\begin{array}{c}\text { Effectif } \\
\text { total }\end{array}$ & $\begin{array}{l}\text { Arts } \\
\text { plastiques } \\
\text { et arts } \\
\text { appliqués }\end{array}$ & Architecture & $\begin{array}{l}\text { Théâtre } \\
\text { et } \\
\text { spectacles }\end{array}$ & $\begin{array}{c}\text { Musique } \\
\text { et } \\
\text { danse }\end{array}$ & $\begin{array}{c}\text { Cinéma } \\
\text { et } \\
\text { audiovisuel }\end{array}$ & Patrimoine \\
\hline Alsace & 5 & 1512 & 679 & 740 & 49 & 44 & III & I/I \\
\hline Aquitaine & 5 & 1254 & 320 & 886 & - & 48 & /II & //I \\
\hline Auvergne & 2 & 620 & 149 & 471 & //I & III & III & III \\
\hline Basse-Normandie & 2 & 251 & 251 & III & III & //I & /II & III \\
\hline Bourgogne & 3 & 333 & 283 & III & I/I & 50 & III & //I \\
\hline Bretagne & 7 & 1646 & 927 & 668 & 15 & 36 & III & III \\
\hline Centre & 4 & 562 & 520 & III & /II & 42 & //I & //I \\
\hline Champagne-Ardenne & 3 & 247 & 186 & III & 61 & /II & //I & //I \\
\hline Franche-Comte & 1 & 208 & 208 & III & III & I/I & III & /II \\
\hline Haute-Normandie & 4 & 913 & 341 & 512 & III & 60 & III & III \\
\hline Île-de-France & 22 & 14363 & 1634 & 8911 & 141 & 1672 & 173 & 1832 \\
\hline Languedoc-Roussillon * & 5 & 1072 & 297 & 762 & 13 & III & III & III \\
\hline Limousin & 1 & 145 & 145 & III & /II & /II & /II & /II \\
\hline Lorraine & 5 & 1160 & 417 & 713 & III & 30 & III & III \\
\hline Midi-Pyrénées & 5 & 1406 & 402 & 858 & I/I & 146 & III & /II \\
\hline Nord-Pas-de-Calais & 8 & 1461 & 565 & 849 & 15 & 32 & //I & III \\
\hline Pays-de-la-Loire & 6 & 1473 & 586 & 811 & //I & 76 & /II & /II \\
\hline Picardie & 1 & 132 & 132 & III & III & /II & III & III \\
\hline Poitou-Charentes & 3 & 350 & 274 & III & /II & 76 & //I & //I \\
\hline Provence-Alpes-Côte d'Azur & 12 & 2234 & 939 & 1005 & 38 & 252 & I/I & III \\
\hline Rhône-Alpes & 12 & 3806 & 1014 & 2060 & 19 & 713 & //I & //I \\
\hline Dom & 2 & 209 & 209 & III & III & III & III & III \\
\hline Total & 118 & 35357 & 10478 & 19246 & 351 & 3277 & 173 & 1832 \\
\hline
\end{tabular}

Source : DEPS, Ministère de la Culture et de la Communication/Ministère de l’Éducation nationale.

4. Ce document ne permet pas d'avoir le nombre total de DE délivrés par le ministère de la Culture et de la Communication. Parmi les centres habilités à préparer ce diplôme, seuls les établissements subventionnés par le ministère de la Culture et de la Communication ont été retenus. 
Carte - Effectif d'élèves dans les établissements d'enseignement supérieur artistique et culturel par région (année scolaire 2006-2007)

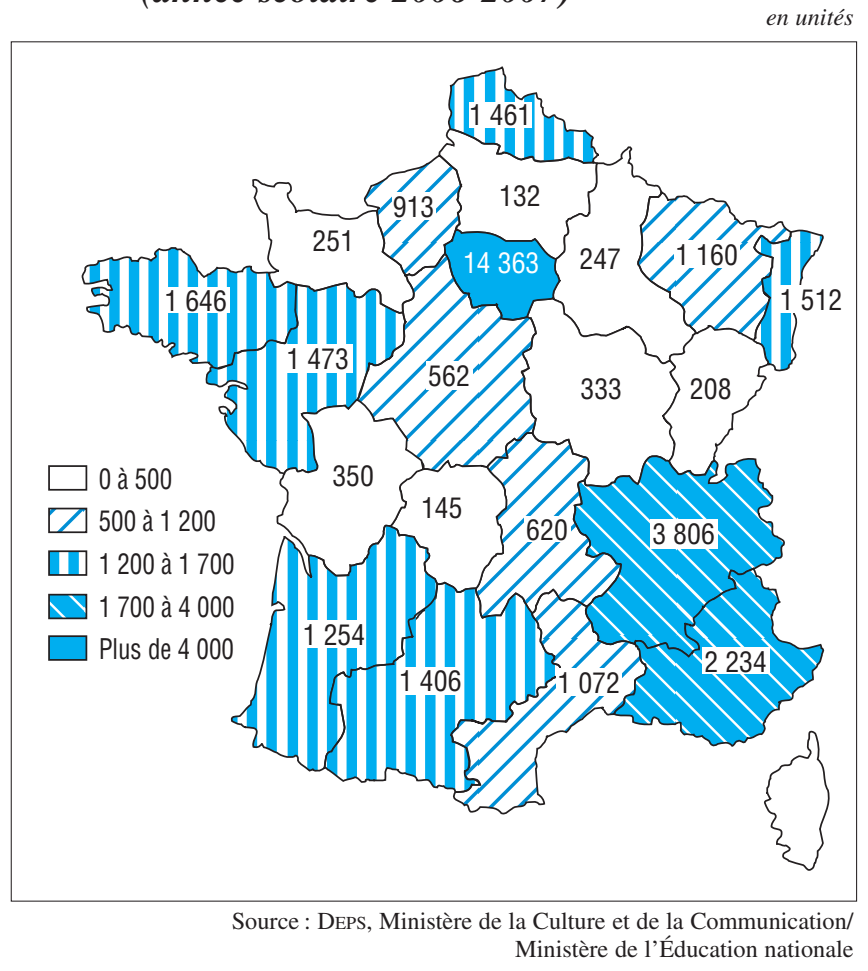

Une partie de ces diplômes a fait l'objet d'un enregistrement au Répertoire national de la certification professionnelle. Cette nouvelle procédure, mise en place dans le cadre de l'harmonisation européenne des diplômes, succède à l'ancien système d'homologation et consiste à classer, par niveaux et par spécialités, les diplômes délivrés par les organismes publics ou privés.

À la fin de l'année scolaire 2005-2006, près de 9500 élèves sont sortis diplômés des formations supérieures artistiques et culturelles. Sur près de 5000 diplômés en architecture, 1500 étudiants ont obtenu le diplôme national de l'architecture (DPLG). Près de 2600 étudiants ont reçu un diplôme national à l'issue de leur scolarité dans une école d'art, dont $5 \%$ ont eu le DNAT, diplôme du cycle court de niveau II ; 60 \% le DNAP, diplôme du cycle long en cours d'inscription; et $35 \%$ le DNSEP, diplôme du cycle long de niveau I.

Dans le domaine du patrimoine, 19 masters ont été délivrés à l'Institut national du patrimoine (INP).

Enfin, 303 diplômes d'État de professeur de musique ou de danse ont été délivrés par les 8 CEFEDEM, les 2 CESMD et par l'école Rosella Hightower.

Tableau 4 - Diplômes délivrés par domaine et par type de diplôme (année scolaire 2005-2006)

\begin{tabular}{|c|c|c|c|c|c|c|}
\hline \multirow[b]{2}{*}{ Domaines } & \multirow[b]{2}{*}{$\begin{array}{c}\text { Diplômes nationaux } \\
\text { de l'enseignement } \\
\text { supérieur }\end{array}$} & \multirow[b]{2}{*}{$\begin{array}{l}\text { Diplômes } \\
\text { nationaux }\end{array}$} & \multicolumn{3}{|c|}{ Diplômes d'établissement et d'université } & \multirow[b]{2}{*}{ Total } \\
\hline & & & Total & $\begin{array}{c}\text { dont } \\
\text { inscrits } \\
\text { au RNCP }\end{array}$ & $\begin{array}{c}\text { dont } \\
\text { homologués }\end{array}$ & \\
\hline Arts plastiques et arts appliqués & /// & 2590 & 482 & 181 & 132 & 3072 \\
\hline Architecture & 3410 & 1501 & //I & //I & /II & 4911 \\
\hline Théâtre et spectacles & III & 39 & //I & //I & //I & 39 \\
\hline $\begin{array}{l}\text { Musique et danse } \\
\text { dont CEFEDEM et CESMD } \\
\text { et CFMl }\end{array}$ & $\begin{array}{l}\text { III } \\
\text { III } \\
\text { /II }\end{array}$ & $\begin{array}{r}336 \\
290 \\
/ 1 /\end{array}$ & $\begin{array}{r}476 \\
1 / 1 \\
131\end{array}$ & $\begin{array}{r}400 \\
1 / 1 \\
131\end{array}$ & $\begin{array}{l}21 \\
\| / I \\
\text { III }\end{array}$ & $\begin{array}{l}812 \\
290 \\
131\end{array}$ \\
\hline Cinéma et audiovisuel & III & III & 40 & I/I & 40 & 40 \\
\hline Patrimoine & /II & 19 & 562 & /II & 110 & 581 \\
\hline Total & 3410 & 4485 & 1560 & 581 & 303 & 9455 \\
\hline
\end{tabular}

Source : DEPS, Ministère de la Culture et de la Communication/Ministère de l'Éducation nationale.

\section{Méthodologie}

Ces données sont issues d'une enquête annuelle du ministère de l'Éducation nationale (Direction de l'évaluation et de la prospective) réalisée en collaboration avec le Département des études, de la prospective et des statistiques du ministère de la Culture et de la Communication. Cette enquête par questionnaire en ligne auprès des établissements concerne les formations supérieures publiques et privées quelle que soit leur tutelle, à l'exception des écoles d'architecture. Les données concernant ces dernières proviennent de l'enquête annuelle de la Direction de l'architecture et du patrimoine du ministère de la Culture et de la Communication.

Signes conventionnels utilisés

$\begin{array}{llll}\ldots & \text { résultat non disponible } & \text { /l/ } & \text { absence de résultat due à la nature des choses } \\ \text { - } & \text { résultat nul } & \mathrm{nr} & \text { non renseigné }\end{array}$

